\title{
BMJ Open Results of Florida's Amyotrophic Lateral Sclerosis Surveillance Project, 2009-2011
}

\author{
Cecilia Freer, ${ }^{1}$ Tara Hylton, ${ }^{2}$ Heather M Jordan, ${ }^{3}$ Wendy E Kaye,${ }^{3}$ Sabrina Singh, ${ }^{2}$ \\ Youjie Huang ${ }^{2}$
}

To cite: Freer C, Hylton T, Jordan HM, et al. Results of Florida's Amyotrophic Lateral Sclerosis Surveillance Project, 2009-2011. BMJ Open 2015;5:e007359. doi:10.1136/bmjopen-2014007359

- Prepublication history for this paper is available online. To view these files please visit the journal online (http://dx.doi.org/10.1136/ bmjopen-2014-007359).

Received 3 December 2014 Revised 12 March 2015 Accepted 18 March 2015

CrossMark

\begin{abstract}
${ }^{1}$ University of Florida, Jacksonville, Florida, USA

${ }^{2}$ Florida Department of Health, Tallahassee, Florida, USA

${ }^{3}$ McKing Consulting Corporation, Atlanta, Georgia, USA
\end{abstract}

Correspondence to Heather M Jordan; hjordan@ mcking.com

\section{ABSTRACT}

Objective: Studies to determine the incidence and prevalence of amyotrophic lateral sclerosis (ALS) in defined geographic areas in the USA are needed. The Florida Department of Health received funding from the federal Agency for Toxic Substances and Disease Registry to implement a state-wide ALS Surveillance Project. The objectives of the project were to describe the demographic characteristics of ALS cases and to calculate the incidence and prevalence of ALS in Florida.

Setting/participants: All neurologists were asked to submit case reports for persons with ALS diagnosed and/or under their care during 1 January 2009 through 31 December 2011. A medical record verification form and an electromyogram (EMG) report were requested for a sample of cases and reviewed by an independent consulting neurologist to confirm ALS diagnosis. Death data were used to aid with case report collection.

Primary and secondary outcome measures: Demographics, relevant history and clinical characteristics, El Escorial classifications, time from symptom onset to diagnosis, crude annual incidence rates and 2009 period prevalence are presented.

Results: The 1450 reported ALS cases were more likely to be older, male, white and non-Hispanic. Slightly more than $4 \%$ of cases were reported as also having dementia, and $4.8 \%$ were reported to have an immediate family member diagnosed with ALS. Incidence rates ranged from 1.7 to 1.9 per 100000 person-years during the project period and the 2009 period prevalence was 4.0 per 100000 persons.

Conclusions: Project findings are generally consistent with findings of population-based studies in Europe, as well as geographically limited studies in the USA. Our findings add to the growing body of epidemiological literature about ALS in the USA. Future epidemiological studies in the USA should focus on identifying cases from minority groups and those that may have limited access to healthcare, and should consider conducting capture-recapture analysis to assess case ascertainment.

\section{INTRODUCTION}

Amyotrophic lateral sclerosis (ALS) is a progressive neurodegenerative disease affecting the central nervous system resulting in loss of

\section{Strengths and limitations of this study}

- This is the first state-wide report on the incidence, prevalence and demographic characteristics of amyotrophic lateral sclerosis (ALS) in Florida. All neurologists, including those at ALS specialty centres and those at general neurology practices, were asked to submit case reports for all patients with ALS under their care in order to obtain as many case reports as possible.

- Successful working relationships were developed with reporting providers and their staff, particularly with specialty centres in the region that diagnose and care for patients with ALS.

- Some physicians refused to report cases, citing concerns for patient confidentiality or the desire to obtain patient consent even though the study had a waiver of informed consent approved by the Institutional Review Board. Despite these limitations, $96.7 \%$ of the expected cases were reported.

- Hospital discharge and death certificate data were examined and attempts were made to collect case reports for decedents that were not reported to the project; 962 unique names were identified in the two databases and 11 of them were reported to the project. It is uncertain what portion of the remaining 951 may actually have been true ALS cases.

motor function. ALS is difficult to diagnose and requires a combination of clinical examinations and a series of diagnostic tests to rule out diseases that mimic ALS. ${ }^{1}$ According to the revised El Escorial Criteria, patients are classified as Definite, Probable, Probable-Lab Supported, Possible and Not Classifiable using information gathered from clinical examinations and electromyography. ${ }^{2}$

Little is known about the aetiology of ALS; fewer than $10 \%$ of cases are genetic. ${ }^{3}$ In their systematic review of 19 studies conducted worldwide, Hirtz et $a l^{4}$ found a median annual incidence rate of 1.6 per 100000 person-years (range of $0.7-2.5$ ), the median point prevalence was 4.0 per 100000 persons, and there was a strong association with increased age. More recently, Chio et $a \tilde{l}$ 
reported a worldwide median incidence rate of 2.1 per 100000 person-years and a point prevalence of 5.4 per 100000 persons.

Few studies have been conducted to determine the incidence and prevalence of ALS in the USA. Most that have been conducted are within limited geographic areas, such as a study conducted in Rochester, Minnesota, which found an incidence rate of 1.7 per 100000 person-years ${ }^{6}$ and a study conducted in selected areas of Texas which found a point prevalence of 1.6 per 100000 persons. ${ }^{7}$ There is a lack of large-scale surveillance efforts to understand the incidence and prevalence of ALS in the USA.

In 2008, President George W Bush signed Public Law No. 110-373, authorising the National ALS Registry. ${ }^{8}$ This population-based Registry, maintained by the Agency for Toxic Substances and Disease Registry (ATSDR), gathers information on patients with ALS through an algorithm that searches existing national databases, including Medicare, Medicaid, Veterans Health Administration and Veterans Benefits Administration. ${ }^{8}{ }^{9}$ Patients diagnosed with ALS also self-enroll through a secure web portal.

In 2010, ATSDR funded state and metropolitan area ALS surveillance projects. The Florida Department of Health $(\mathrm{FDOH})$ received funding to implement a statewide ALS surveillance project. The Florida ALS Surveillance Project served two purposes: (1) to help determine the completeness of the Registry; and (2) to describe the incidence, prevalence and demographic characteristics of ALS in Florida. This paper describes the data collection methodology, the incidence and prevalence of ALS in Florida, and the demographic characteristics of Floridians diagnosed with ALS.

\section{METHODS}

Project staff worked with FDOH's Medical Quality Assurance Board (MQA) to provide a list of all physicians practising in Florida with neurology listed as a specialty during each year of the Project. We then removed physicians that specialised in areas such as vascular neurology, paediatric neurology and neurosurgery in urban areas. Physicians who were found to be retired, to have moved out of state or to be deceased were also removed.

The identified neurologists were contacted via telephone, letter and fax to determine if they diagnosed and/or cared for patients with ALS during the threeyear Project period (1 January 2009 through 31 December 2011). Neurologist who indicated that they had diagnosed and/or provided care during the Project period were provided information about the Project, including a brief summary of the Project's goals, authority of FDOH to collect the requested patient information, and a list of frequently asked questions. Special emphasis was placed on contacting academic centres and ALS specialty clinics, typically seeing more than 50 patients per year, and in-person meetings were conducted with these sites to encourage their participation.
A point of contact was identified at each practice to help facilitate participation in the Project.

Based on population data for each year of the Project, an expected incidence of 2.0 per 100000 person-years, and an expected prevalence of 4.0 per 100000 persons, we expected to collect 1505 unique cases. ${ }^{4}{ }^{10}$ Neurologists were asked to report persons diagnosed and/or under their care for ALS from 1 January 2009 through 31 December 2011. Persons with ALS that were diagnosed before 2009 were reported as long as they were under the neurologists' care on or after 1 January 2009. Incident and prevalent cases were collected. Patient data were captured through Case Reporting Forms completed by neurologists and their office staff after a review of the patient's medical chart. The Case Reporting Form, consisting of 15 questions, collected demographic data, date of diagnosis and date of symptom onset, revised El Escorial criteria classification, if an immediate family member (ie, parent, sibling, child) had been diagnosed with ALS, if the patient had a dementia diagnosis and payer type (eg, insurance type, self-pay). Physicians were provided compensation to offset expenses related to case reporting.

To ensure accuracy of diagnosis, a sample of cases was selected for further review. Cases were selected for verification using both a systematic sample of all cases and targeted selection of unusual cases, for example, those $<40$ years of age or those with a diagnosis before 1999 . Smaller neurology practices, defined as those diagnosing and/or caring for five or fewer patients with ALS during the Project period, were asked to submit a Medical Records Verification Form on all reported patients, while larger practices and ALS specialty clinics submitted forms for a small percentage of their reported cases. The Medical Record Verification Form collected data on the patient's symptoms and whether or not the patient was prescribed Rilutek, the only drug approved for the treatment of ALS. A copy of the patient's most recent electromyogram (EMG) report was also requested. These were reviewed by the Project's consulting neurologist who is an expert in the diagnosis and care of ALS. The consulting neurologist classified each case according to the revised El Escorial criteria ${ }^{2}$ based on this information. Cases determined not to have ALS by the consulting neurologist were removed from the data set.

The state's hospital discharge database (HD) and death certificate database (DC) were also reviewed to help identify possible cases of ALS that neurologists may not have reported. For the HD database, records were searched using the International Classification of Diseases (ICD), Revision 9 code for ALS (335.20). ${ }^{11}$ For the DC database, records were searched using ICD-10 code for motor neuron disease (G12.2).$^{12}$ Attempts were made to collect case reports for decedents that were not already reported by neurologists.

Incidence was calculated for each Project year. The state's population for the specific year was used as the denominator ${ }^{10}$ and the number of new ALS patients 
reported by year was used as the numerator. Average annual incidence rates were calculated by adding the incidence rates for the 3 years and then dividing by three. A Poisson distribution was assumed in the calculation of the 95\% CI and differences in incidence rates between subgroups were considered significant if the CIs did not overlap. Period prevalence was calculated for 2009 only by using the state's population as the denominator and the number of ALS cases alive in 2009 regardless of the year of diagnosis.

No patients were contacted. The Project was approved by the Centers for Disease Control and Prevention Institutional Review Board (IRB) and determined to be public health practice not requiring review by the FDOH IRB.

\section{RESULTS}

The MQA provided the names of more than 2500 physicians in Florida who indicated neurology as a specialty. After removing those not likely to diagnose or treat patients with ALS, there were 862 neurologists to be contacted. Of these 862 neurologists, (29.9\%) acknowledged that they had diagnosed and/or cared for patients with ALS during the Project period. Of these, 57.4\% submitted case reports. These 148 physicians represented 96 practices located throughout the state. All ALS specialty centres in the state reported cases.

A review of the state's HD and DC databases yielded a total of 962 unique names that had not been reported; 390 in the HD database only, 338 in the DC database only, and 234 listed in the HD and DC databases. Follow-up with neurologists that could be identified via a review of death certificates resulted in 11 additional case reports.

A total of 1843 case reports were received. Of these reports, $20.9 \%$ were duplicate cases reported by more than one neurologist at different practices. Fifteen per cent of submitted case reports were selected for verification. Medical records verification forms were received for $70.4 \%$ of those requested, and $10.2 \%$ of all case reports received. Seven cases were removed because of case verification process when the diagnosis could not be confirmed, resulting in 1450 unique case reports, which was $96.7 \%$ of the expected cases. ${ }^{410}$

Of the 1450 cases that were reported, $82.7 \%$ were diagnosed after age 50 years, $57.9 \%$ were male, $73.0 \%$ were white, $74.8 \%$ were non-Hispanic (table 1 ).

The ratio of men to women who were reported to have ALS was 1.4:1. An immediate family member with ALS was reported for $4.8 \%$ of the cases. A dementia diagnosis was reported for $4.3 \%$ of the cases.

The neurologists' reported revised El Escorial classification for $79.1 \%$ of all reported cases and for $79.6 \%$ of incident cases diagnosed in 2009-2011 was Definite, Probable or Probable-Lab Supported (table 2).

Data on time from symptom onset to diagnosis were available for $82.3 \%$ of the cases. Fifty per cent of the cases experiences symptoms for 11 months or less
Table 1 Demographic characteristics of all reported ALS cases in Florida, 2009-2011 $(n=1450)$

\begin{tabular}{|c|c|c|c|c|}
\hline \multirow{2}{*}{$\begin{array}{l}\text { Demographic } \\
\text { characteristic }\end{array}$} & \multicolumn{2}{|l|}{$\begin{array}{l}2010 \text { Florida } \\
\text { population* }\end{array}$} & \multicolumn{2}{|c|}{ ALS cases } \\
\hline & $\mathbf{N}$ & $\% \dagger$ & $\overline{\mathbf{N}}$ & $\% \dagger$ \\
\hline \multicolumn{5}{|l|}{ Age (in years) } \\
\hline$<40$ & 9209760 & 50.0 & 80 & 5.5 \\
\hline $40-49$ & 2653989 & 14.1 & 161 & 11.1 \\
\hline $50-59$ & 2542709 & 13.5 & 309 & 21.3 \\
\hline $60-69$ & 2094483 & 11.1 & 450 & 31.0 \\
\hline $70-79$ & 1384221 & 7.4 & 337 & 23.2 \\
\hline$\geq 80$ & 916148 & 4.9 & 104 & 7.2 \\
\hline Unknown & NA & NA & 9 & 0.6 \\
\hline \multicolumn{5}{|l|}{ Sex } \\
\hline Male & 9189355 & 48.9 & 839 & 57.9 \\
\hline Female & 9611955 & 51.1 & 611 & 42.1 \\
\hline \multicolumn{5}{|l|}{ Race } \\
\hline White & 14109162 & 75.0 & 1058 & 73.0 \\
\hline Black & 2999862 & 16.0 & 89 & 6.1 \\
\hline Asian & 454821 & 2.4 & 17 & 1.1 \\
\hline Other & 1237465 & 6.6 & 5 & 0.3 \\
\hline Unknown & NA & NA & 281 & 19.4 \\
\hline \multicolumn{5}{|l|}{ Ethnicity } \\
\hline Hispanic & 4223806 & 22.5 & 155 & 10.7 \\
\hline Non-hispanic & 14577504 & 77.5 & 1085 & 74.8 \\
\hline Unknown & NA & NA & 210 & 14.5 \\
\hline Total & 18801310 & 100.0 & 1450 & 100.0 \\
\hline
\end{tabular}

*US Census Bureau, 2011.

†May not add up to $100 \%$ due to rounding.

before diagnosis and $90 \%$ of the cases were diagnosed within 3 years of symptom onset.

There were 1021 cases diagnosed in 2009-2011. The incidence rates were $1.71,1.79$, and 1.93 per 100000 person-years for 2009, 2010, and 2011, respectively. The average annual incidence rate was 1.81 per 100000 person-years. The average annual incidence rates between males (2.13 per 100000 person-years; 95\% CI 1.83 to 2.42 ) and females (1.51 per 100000 personyears; $95 \%$ CI 1.26 to 1.75 ), between whites (1.77 per 100000 person-years; 95\% CI 1.55 to 1.99 ) and blacks (0.68 per 100000 person-years; $95 \%$ CI 0.38 to 0.97 ),

Table 2 El Escorial criteria classification of reported ALS cases in Florida, 2009-2011

\begin{tabular}{|c|c|c|c|c|}
\hline \multirow{2}{*}{$\begin{array}{l}\text { Reported EI Escorial } \\
\text { criteria classification }\end{array}$} & \multicolumn{2}{|c|}{$\begin{array}{l}\text { All reported } \\
\text { cases }\end{array}$} & \multicolumn{2}{|c|}{$\begin{array}{l}\text { Incident } \\
\text { cases } \\
\text { diagnosed } \\
\text { 2009-2011 }\end{array}$} \\
\hline & $\mathbf{N}$ & $\%$ & $\mathbf{N}$ & $\%$ \\
\hline Definite & 664 & 45.8 & 441 & 43.2 \\
\hline Probable & 338 & 23.3 & 254 & 24.9 \\
\hline Probable-lab supported & 145 & 10.0 & 117 & 11.5 \\
\hline Possible & 193 & 13.3 & 131 & 12.8 \\
\hline Not classifiable & 110 & 7.6 & 78 & 7.6 \\
\hline Total & 1450 & 100.0 & 1021 & 100.0 \\
\hline
\end{tabular}




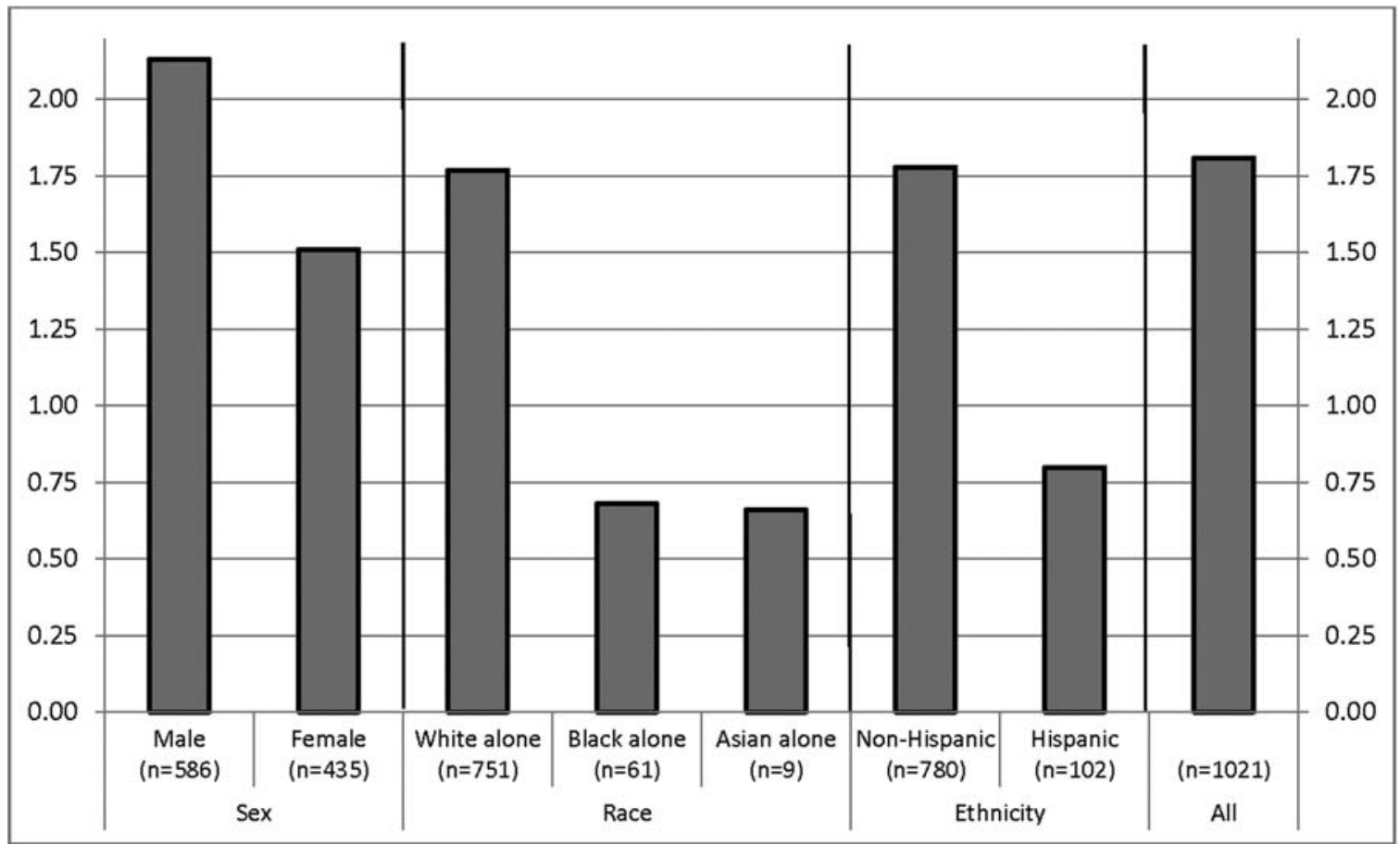

Figure 1 Stratified average annual incidence rates (per 100000 person-years) for ALS cases diagnosed 1 January 2009 through 31 December 2011 in Florida $(n=1021)$. $Y$ axis: average annual incidence rates (per 100000 person-years). $X$ axis: sex (male and female), race (White, Black and Asian), ethnicity (Non-Hispanic and Hispanic) and all.

between whites (1.77 per 100000 person-years; 95\% CI 1.55 to 1.99$)$ and Asians (0.66 per 100000 person-years; $95 \%$ CI 0.00 to 1.41$)$ and between Hispanics $(0.80$ per 100000 person-years; $95 \%$ CI 0.53 to 1.08$)$ and non-Hispanics (1.78 per 100000 person-years; 95\% CI 1.57 to 2.00 ) were significantly different (figure 1 ). There were 742 cases with a diagnosis by 31 December 2009; the period prevalence for 2009 was 3.95 per 100000 persons.

\section{DISCUSSION}

The Florida ALS Surveillance Project was the FDOH's first effort at conducting surveillance on a non-reportable disease. A total of 148 neurologists representing 96 practices throughout the state submitted 1843 case reports. After deduplication, $96.7 \%$ of the expected cases were retained in the final data set. Therefore, we are confident that we collected the majority of eligible cases.

This distribution of demographic characteristics is similar to other published data. ${ }^{4} 71314$ The incidence rates for each year of the project period ranged from 1.71 to 1.93 per 100000 person-years, which are within the range described in the USA and around the world. ${ }^{451314}$ Our findings with regard to differences in incidence rates between males and females, between whites and blacks, between whites and Asians, and between Hispanics and non-Hispanics are similar to previous reports. ${ }^{5}$ 14-18

In addition, the 12-month period prevalence for 2009 was 3.95 per 100000 persons which is consistent with the recently published Morbidity and Mortality Weekly Report (MMWR). ${ }^{9}$ The MMWR noted a nation-wide 14-month period prevalence of 3.90 per 100000 persons using a multiple sources to determine case eligibility. Specifically, ATSDR applies an algorithm to national administrative data sets and examined patient selfenrollment in the National ALS Registry to determine eligible ALS cases. While the Florida ALS Surveillance Project conducted case ascertainment activities among neurologists, the national approach conducted by ATSDR uses multiple sources is consistent with other population-based prospective registries in Europe. ${ }^{19}$ Although the reported period prevalence in Florida was found to be consistent with the nation-wide report, it is possible that some ALS cases were not seen by neurologists and thus may not have been reported. A comparison of the Florida data set and the national data set is warranted to understand potential gaps in case reporting, such as certain subgroups, that is, the elderly. Further, the current study was not able to determine survival status of reported cases, therefore reporting point prevalence was not appropriate. Caution is advised when comparing our estimates of period prevalence to point prevalence estimates reported in the literature.

More than 22\% of Florida's population is Hispanic, compared with $11 \%$ of reported cases. This discrepancy may be explained by nearly $15 \%$ of cases listing the patient's ethnicity as unknown. Several physicians noted that the patient's chart did not contain information regarding ethnicity, and a few large ALS clinics noted that their electronic medical record systems did not have 
a field to gather this information. The lower percentage of Hispanic cases could reflect a true discrepancy; recent studies have suggested that the true rate of ALS in the Hispanic population is lower than in the non-Hispanic population. ${ }^{17}{ }^{18}$ It is also possible the Hispanics are less likely to seek or have access to specialty care. ${ }^{20}$

The percentage of cases reported with either a family history of ALS (4.8\%) or having a dementia diagnosis $(4.3 \%)$ was lower in our project compared with previous reports. ${ }^{21-24}$ Our findings may be due to a high percentage of missing data for these two questions. These data may not have been available in the patient's chart, or there may have been a misunderstanding of 'immediate family' (some case reports were returned with notes stating that a patient's aunt, uncle or cousin had ALS). Further, diagnosis of early frontotemporal lobe dementia is difficult and many patients with dementia may go undiagnosed, including those who are no longer verbal or those whose physicians do not specifically screen for dementia. ${ }^{19}$

There is currently no clinical test to determine if a patient has ALS. Disease progression, as well as tests ruling out other conditions, is often used to make a diagnosis. ${ }^{2}$ Given this limitation, there is a concern that ALS can be misdiagnosed. To assess the completeness of the project's case ascertainment, the state's DC data set was reviewed to help identify cases of ALS that were not reported. A study in South Carolina found that on inspection of medical records of patients identified in the state's morbidity data with the ICD-10 code of G12.2 85\% had information in their medical charts that would support an ALS diagnosis according to the El Escorial Criteria. ${ }^{25}$ Only $65 \%$ of death certificates coded with ICD-10 code G12.2 had medical documentation that supported an ALS diagnosis and $18 \%$ had an 'alternative neurological diagnosis'. We were only able to obtain $2.3 \%$ of the potential cases identified from the DC database reported to the project because of the difficulty in identifying a neurologist who could report the case. However, based on the experience in South Carolina, many of these potential cases may not actually have had a diagnosis of ALS.

Of the seven cases that were removed due to inability to confirm the diagnosis with information gathered from the Medical Records Verification Form, over half were patients seen by the reporting neurologist after having received a diagnosis elsewhere. The patient's symptom history may not have been available, and in at least one case, the diagnosing physician was located at an ALS specialty clinic outside of Florida. In at least two cases, physicians reported patients for whom they had ordered medical devices (eg, walkers), but had not completed a medical history or completed tests to confirm the ALS diagnosis. In these cases, the patients were seen by the reporting physician after receiving an ALS diagnosis and after the disease had progressed. It is likely that these cases would not have been removed from the final data set if the diagnosing physician could have been contacted for further information, and is not an indication of error in the diagnosis.

This surveillance project relied on neurologists' reporting of patients with ALS within a defined time frame. Despite a lengthy process of contacting physicians numerous times through letters, phone calls, faxes, office visits and conference attendance, only $57 \%$ of physicians who acknowledged providing care for patients with ALS reported cases. Some physicians refused to report cases, citing concerns for patient confidentiality or desiring to obtain patient consent despite having a waiver of informed consent. In many cases, physicians and office staff had to be educated about the role of the FDOH in gathering data to calculate the incidence and prevalence of diseases. However, all ALS specialty centres in the state participated and reported the majority of cases, and $96.4 \%$ of the expected unique case reports were collected.

Another obstacle was the lack of participation by all but one Veterans Affairs (VA) hospital in the state. The process for obtaining approval from each VA hospital to provide patient information is not centralised; therefore, it was necessary to identify, contact and persuade a neurologist on staff to complete the lengthy approval process with each location's privacy officer. It is likely that some unique cases were not reported due to the lack of participation by VA hospitals.

Data gathered from the review of hospital discharge and death certificate data were to be used to identify a neurologist for each patient, who would then be contacted and encouraged to report eligible cases. Death certificates were often signed by physicians who were unfamiliar with the decedent, or the only physician identified with the patient was a family physician, therefore locating a treating neurologist for the decedent was difficult. Similar issues arose with identifying patients from hospital discharge records; in most cases the physician listed for the patient was a hospitalist, or a physician who otherwise had no record of the patient beyond their hospital visit. Hospitalists were unable to report ALS cases because patient records are the property of the hospital, not the physician. There were a total of 962 unique names identified in the two databases and 11 of them were reported to the project. It is uncertain what portion of the remaining 951 may actually have been true ALS cases. It is possible that some of the patients that appeared in the HD database did not have a Florida residence, which was a requirement for case eligibility.

Some physicians admitted that reporting was not worth their time, due to the low number of cases seen, and the belief that their patients would be reported by larger practices where a patient may have sought second opinions or for comprehensive care. Despite these limitations, $96.7 \%$ of the expected cases in Florida that were diagnosed and/or under a neurologist's care for the period 1 January 2009 through 31 December 2011 were collected. 


\section{CONCLUSIONS}

Conducting surveillance for a non-reportable disease, such as ALS, is a time-consuming effort. Despite the limitations of this project, $96.7 \%$ of expected cases were reported. The data collected by the Florida ALS Surveillance project were consistent with previously published data and add to the epidemiological literature in the US. These findings can be used by neurologists, other healthcare providers and patient services groups to better understand the number and demographic characteristics of persons with ALS in Florida.

Acknowledgements The authors thank all of the reporting providers and their staff members, the Florida ALSA Chapter and other organisations that assisted with Project promotion and data collection, Dr Eric Sorenson from the Mayo Clinic for serving as a consulting neurologist and Ms Lindsay Rechtman, Programme Coordinator, McKing Consulting Corporation, for her technical expertise.

Contributors WEK, CF, TH and YH took part in study concept and design. CF SS, TH, YH and WEK took part in acquisition of data. CF, WEK, HMJ, SS, TH and $\mathrm{YH}$ took part in analysis and interpretation of data. CF, WEK, HMJ, SS, $\mathrm{TH}$ and $\mathrm{YH}$ took part in drafting of the manuscript. CF, HMJ, WEK, TH took part in statistical analysis. TH, WEK and YH took part in study supervision.

Funding This project was funded by McKing Consulting Corporation through a contract funded by the Agency for Toxic Substances and Disease Registry (Contract \#200-2009-32577).

Competing interests None declared.

Ethics approval CDC IRB.

Provenance and peer review Not commissioned; externally peer reviewed.

Data sharing statement No additional data are available.

Disclaimer The findings and conclusions in this manuscript are those of the authors and do not necessarily represent the views of the Agency for Toxic Substances and Disease Registry.

Open Access This is an Open Access article distributed in accordance with the Creative Commons Attribution Non Commercial (CC BY-NC 4.0) license, which permits others to distribute, remix, adapt, build upon this work noncommercially, and license their derivative works on different terms, provided the original work is properly cited and the use is non-commercial. See: http:// creativecommons.org/licenses/by-nc/4.0/

\section{REFERENCES}

1. Eisen A. Amyotrophic lateral sclerosis: a review. $B C$ Med J 2002;44:362-6.

2. Brooks BR, Miller RG, Swash M, et al. El Escorial revisited: revised criteria for the diagnosis of Amyotrophic Lateral Sclerosis. World Federation of Neurology Research Group on Motor Neuron Diseases. Amyotroph Lateral Scler Other Motor Neuron Disord 2000;1:293-9.

3. Byrne S, Walsh C, Lynch C, et al. Rate of familial amyotrophic lateral sclerosis: a systematic review and meta-analysis. J Neurolo Neurosurg Psychiatry 2011;82:623-7.
4. Hirtz D, Thurman D, Gwinn-Hardy K, et al. How common are the "common" neurologic disorders? Neurology 2007;68:326-37.

5. Chio A, Logrosino G, Traynor BJ, et al. Global epidemiology of amyotrophic lateral sclerosis: a systematic review of the published literature. Neuroepidemiology 2013;41:118-30.

6. Sorenson J, Stalker A, Kurland L, et al. Amyotrophic lateral sclerosis in Olmsted County, Minnesota, 1925 to 1998. Neurology 2002;59:280-2.

7. Wagner L, Archer NP, Williamson DM, et al. Prevalence of amyotrophic lateral sclerosis in Texas, 1998-2003. Tex Med 2012;108:e1.

8. Antao V, Horton D. The national amyotrophic lateral sclerosis (ALS) registry. J Environ Health 2012;74:28-30.

9. Mehta P, Antao V, Kaye W, et al. Prevalence of amyotrophic lateral sclerosis-United States, 2010-2011. MMWR Morb Morta Wkly Rep 2014;63(Suppl 7):1-13.

10. United States Census Bureau. State and County QuickFacts. United States Census Bureau/American Factfinder Web site 2011. http:// quickfacts.census.gov/qfd/states/12000.html (accessed 23 Jun 2014).

11. United States Department of Health and Human Services. International classification of diseases, 9th revision, clinical modifications (ICD-9-CM), 6th edn. DHHS Publication No. (PHS) 96-1260. Washington, DC: Health Care Financing Administration, 1997.

12. World Health Organization. International statistical classification of diseases and related health problems, Tenth revision. Geneva: World Health Organization, 1992.

13. Logroscino G, Traynor B, Hardiman O, et al. Incidence of amyotrophic lateral sclerosis in Europe. $J$ Neurol Neurosurg Psychiatry 2010;81:385-90

14. Jordan $\mathrm{H}$, Fagliano J, Rechtman L, et al. Population-based surveillance of amyotrophic lateral sclerosis in New Jersey, 2009-2011. Neuroepidemiology 2014;43:49-56.

15. Fong GCY, Cheng TS, Lam K, et al. An epidemiological study of motor neuron disease in Hong Kong. Amyotroph Lateral Scler 2005;6:164-8.

16. Gundogdu B, Al-Lahham T, Kadlubar F, et al. Racial differences in motor neuron disease. Amyotroph Lateral Scler Frontotemporal Degener 2014;15:114-18.

17. Zaldivar T, Gutierrez J, Lara G, et al. Reduced frequency of ALS in an ethnically mixed population: a population-based mortality study. Neurology 2009;72:1640-5.

18. Cronin S, Hardiman O, Traynor BJ. Ethnic variation in the incidence of ALS: a systematic review. Neurology 2007;68:1002-7.

19. Logroscino G, Traynor BJ, Hardiman O, et al. Descriptive epidemiology of amyotrophic lateral sclerosis: new evidence and unsolved issues. J Neurol Neurosurg Psychiatry 2008;79:6-11.

20. Balluz LS, Okoro CA, Strine TW. Access to health care and preventive services among Hispanics and non-Hispanics-United States. MMWR Morb Morta Wkly Rep 2004;53:937-41.

21. Traynor BJ, Codd MB, Corr B, et al. Clinical features of amyotrophic lateral sclerosis according to the El Escorial and Airlie House diagnostic criteria: a population-based study. Arch Neurol 2000;57:1171-6.

22. O'Toole O, Traynor BJ, Brennan P, et al. Epidemiology and clinical features of amyotrophic lateral sclerosis in Ireland between 1995 and 2004. J Neurol Neurosurg Psychiatry 2008;79:30-2.

23. Phukan J, Elamin M, Bede P, et al. The syndrome of cognitive impairment in amyotrophic lateral sclerosis: a population-based study. J Neurol Neurosurg Psychiatry 2012;83:102-8.

24. Ringholz G, Appel S, Bradshaw M, et al. Prevalence and patterns of cognitive impairment in sporadic ALS. Neurology 2005:65:586-90.

25. Stickler DE, Royer JA, Hardin JW. Accuracy and usefulness of ICD-10 death certificate coding for the identification of patients with ALS: results from the South Carolina ALS Surveillance Pilot Projects. Amyotroph Lateral Scler 2012;13:69-73. 